\title{
Additional Treatment Modality to Improve Outcomes in Myocardial Infarctions and Strokes
}

\author{
Simon Skurkovich ${ }^{1}$, Boris Skurkovich ${ }^{2}$ \\ ${ }^{1}$ Advanced Biotherapy Laboratories, Rockville, USA \\ ${ }^{2}$ Warren Alpert Medical School of Brown University, Providence, USA \\ Email: *sskurkovich@gmail.com
}

Received 31 March 2014; revised 10 April 2014; accepted 17 April 2014

Copyright (C) 2014 by authors and Scientific Research Publishing Inc.

This work is licensed under the Creative Commons Attribution International License (CC BY).

http://creativecommons.org/licenses/by/4.0/

(c) (i) Open Access

\section{Abstract}

In 1974, in Nature, we hypothesized that removal of cytokines can be effective in the treatment of certain inflammatory diseases, e.g., rheumatoid arthritis (RA). We call this approach anticytokinotherapy. Later it was shown that neutralization of pro-inflammatory cytokines, such as tumor necrosis factor alpha (TNF- $\alpha$ ), interferon alpha (IFN- $\alpha$ ), interferon gamma (IFN- $\gamma$ ), and interleukin 6 (IL-6), leads to a good therapeutic effect. Anticytokinotherapy is currently used around the world for the treatment of rheumatoid arthritis, psoriasis, psoriatic arthritis, and other Th-1-mediated inflammatory diseases. Pro-inflammatory cytokines have also been found in other conditions (myocardial infarctions, strokes, chronic pain syndromes, etc.). This leads us to believe that hyperproduction of pro-inflammatory cytokines forms a basis of a variety of pathological conditions and represents a uniform response of the organism to a wide variety of insults in any part of the body. Thus, we propose to add monoclonal antibodies to (or other blockers of) pro-inflammatory cytokines to the treatment regimens for myocardial infarctions, strokes, and possibly other Th-1-mediated diseases.

\section{Keywords}

Neutralization of Pro-Inflammatory Cytokines, Myocardial Infarction, Stroke

Cytokines can be found in the circulation in very small concentrations $(\mathrm{pg} / \mathrm{ml})$ and they affect target cells through their specific receptors. Binding of cytokines to the receptors on target cells leads to the expression of a number of genes. Cytokines also play a role in communication between the immune system and hematopoiesis, as well as with endocrine and nervous systems. Through cytokines immune system regulates other organs and

\footnotetext{
${ }^{*}$ Corresponding author.
}

How to cite this paper: Skurkovich, S. and Skurkovich, B. (2014) Additional Treatment Modality to Improve Outcomes in Myocardial Infarctions and Strokes. Journal of Immune Based Therapies, Vaccines and Antimicrobials, 3, 29-31. 
tissues, activates or suppresses their function, regulates metabolism and physiological, reparative, and regenerative processes. In some cases cytokines work as anti-inflammation agents, in others they stimulate inflammation. Any biological response of the organism is connected to cytokines. In general, normal function of cytokines defines normal functioning of the organism. Any abnormality of cytokine function causes disease.

For example, TNF- $\alpha$ plays a major role in apoptosis by binding to one of its receptors (R1) and initiating caspase activation via TNF receptor-associated death domain. At the same time TNF is a cytokine that often works together with IFN- $\gamma$ and the latter activates the function of the former. IFN- $\gamma$, the most important immune regulator, plays a very important role in the organism. Even a minimal abnormality in its synthesis leads to serious consequences. Definitely, cytokines are the functional system that provides the organism with homeostasis.

In the 1960s and 1970s only a limited number of cytokines were discovered-interferons alpha, beta, and gamma. Interferons were considered to be anti-viral agents that also had limited ability to decrease proliferation of tumor cells. In 1973, in Immunology, we demonstrated that interferon has other functions, particularly being an important mediator of the immune system [1].

In 1974, in Nature, we proposed to use antibodies against pro-inflammatory cytokines in autoimmune diseases [2] and were the first to suggest treatment of autoimmune diseases with antibodies to TNF- $\alpha$, IFN- $\alpha$, and IFN$\gamma$ [3]. Currently, anticytokinotherapy is widely used for the treatment of rheumatoid arthritis, psoriasis, and other Th-1-mediated diseases [4]-[6].

Further research showed that pro-inflammatory cytokines (IFN- $\gamma$, TNF- $\alpha$, IL-6, and others) were found in myocardial infarctions and strokes [7] [8] as well as in patients with persistent pain, Alzheimer disease, and other Th-1-mediated diseases. Post-inflammatory changes (adhesions, scars, necrosis, and others) lead to decrease in the function of organs that have been affected by inflammation. Thus, in order to decrease inflammation that plays such a central role in these diseases one should administer substances that would neutralize pro-inflammatory cytokines leading to alleviation of patients' condition. For example, in patients with myocardial infarction a combination of antibodies to, or blockers of pro-inflammatory cytokines, or an antibody to a single proinflammatory cytokine needs to be administered as soon as possible after the acute event has occurred. These antibodies can be administered intravenously, intramuscularly, via iontophoresis, or directly to the site via cardiac catheterization. In strokes antibodies can be administered intravenously, intramuscularly, or via iontophoresis. Both in myocardial infarctions and strokes antibodies should be administered continuously for at least seven days.

It is entirely possible to select antibodies to appropriate pro-inflammatory cytokines to treat pancreatitis, cholecystitis, and nephritis the same way different forms of colitis are currently treated with antibodies to pro-inflammatory cytokines. It is also possible to treat complications of schizophrenia, autism, Alzheimer's disease, and other diseases of the central nervous system.

In all instances antibodies have to be administered in large doses continuously and patients' cytokine levels have to be carefully monitored. We believe that this approach will lead to significant decrease in inflammation and improvement in patients' health.

In the organism there are both pro- and anti-inflammatory cytokines. It is important to note that it is the balance of pro- and anti-inflammatory cytokines that determines normal homeostasis. In Th- 1 autoimmune diseases this balance is disturbed with predominance of pro-inflammatory cytokines. In our view, in TH-2-mediated diseases like scleroderma, fibromyalgia, and others it is the predominance of anti-inflammatory cytokines that needs to be corrected by neutralization of IL-4, IL-13, TGF- $\beta$, and others. This topic has not been studied in depth yet [9] [10].

\section{References}

[1] Skurkovich, S.V., Klinova, E.G., Aleksandrovskaya, I.M., Levina, N.V., Arkhipova, N.A. and Bulicheva, T.I. (1973) Stimulation of Transplantation Immunity and Plasma Cell Reaction by Interferon in Mice. Immunology, 25, 317-322.

[2] Skurkovich, S.V., Klinova, E.G., Eremkina, E.I. and Levina, N.V. (1974) Immunosuppressive Effect of an Anti-Interferon Serum. Nature, 247, 551-552. http://dx.doi.org/10.1038/247551a0

[3] Skurkovich, S. and Skurkovich, B. (1989) The Development of Autoimmune Diseases is Connected with the Initial Disturbance of Interferon Synthesis in the Cells. Journal of Interferon Research, 9, S305.

[4] Skurkovich, S.V., Loukina, G.V., Sigidin, Y.A. and Skurkovich, B. (1998) Successful First-Time Use of Antibodies to Interferon-Gamma Alone and Combined with Antibodies to Tumor Necrosis Factor Alpha to Treat Rheumatic Diseases (Rheumatoid Arthritis, Systemic Lupus Erythemotosus, Psoriatic Arthritis, Behcet’s Syndrome). Intern Journal of 
Immunotherapy, 14, 23-32.

[5] Elliott, M.J., Maini, R.N., Feldmann, M., Kalden, J.R., Antoni, C., Smolen, J.S., Leeb, B., Breedveld, F.C., Macfarlane, J.D., Bijl, H. and Woody, J.N. (1994) Randomized Double-Blind Comparison of Chimeric Monoclonal Antibody to Tumor Necrosis Factor Alpha (cA2) versus Placebo in Rheumatoid Arthritis. Lancet, 344, 1105-1110. http://dx.doi.org/10.1016/S0140-6736(94)90628-9

[6] Skurkovich, B. and Skurkovich, S. (2006) Inhibition of IFN- as a Method of Treatment of Various Autoimmune Diseases, Including Skin Diseases. Ernst Schering Res Found Workshop, 56, 1-27. http://dx.doi.org/10.1007/3-540-37673-9 1

[7] Sharma, H.S. and Das, D.K. (1997) Role of Cytokines in Myocardial Ischemia and Reperfusion. Mediators Inflammation, 6, 175-183. http://dx.doi.org/10.1080/09629359791668

[8] Starke, R.M., Raper, D.M., Ding, D., Chalouhi, N., Owens, G.K., Hasan, D.M., Mendel, R. and Dumont, A.S. (2013) Tumor Necrosis Factor-Modulates Cerebral Aneurism Formation and Rupture. Translational Stroke Research, 5, 269277. http://www.ncbi.nlm.nih.gov/pubmed/24323710

[9] Simms, R.W. and Korn, J.H. (2002) Cytokine Directed Therapy in Scleroderma: Rationale, Current Status, and the Future. Current Opinion in Rheumatology, 14, 717-722. http://dx.doi.org/10.1097/00002281-200211000-00015

[10] Canady, J., Karrer, S., Fleck, M. and Bosserhoff, A.K. (2013) Fibrosing Connective Tissue Disorders of the Skin: Molecular Similarities and Distinctions. Journal of Dermatological Science, 70, 151-158. http://dx.doi.org/10.1016/j.jdermsci.2013.03.005 